\title{
GULTURE OF MOUSE OOGYTES IN VITRO, USING A SYSTEM WITHOUT OIL OR PROTEIN
}

\author{
A. A. HAIDRI, I. M. MILLER AND R. B. L. GWATKIN \\ Merck Institute for Therapeutic Research, \\ Rahway, New Jersey, U.S.A.
}

(Received 17th March 1971)

Summary. Maturation of mouse oocytes in vitro was found to require a critical partial pressure of oxygen, but there was no need for a fixed nitrogen source in the medium. On the basis of these results, a new culture system was devised which eliminates the need for oil or protein.

Culture of mouse oocytes from germinal vesicle to extrusion of the first polar body and second metaphase is now performed using drops of proteinaceous media placed on the bottom of a Petri-dish under a layer of mineral oil (Biggers, Whittingham \& Donahue 1967; Kennedy \& Donahue, 1969). Such systems have drawbacks. The oil layer dissolves medium components of interest, such as steroids, and the protein renders the medium undefined. To overcome these problems, we have investigated the effect of eliminating the oil layer and substituting polyvinylpyrrolidone (PVP) for the protein.

Oocytes were collected from 12- to 15-week-old Swiss mice as described by Biggers et al. (1967) and groups of ten were placed in each well of a Microtest Plate (Falcon Plastics, Cat. No. 3034). Previously, the wells had each received $20 \mu \mathrm{l}$ of medium, consisting of a modified Krebs-Ringer bicarbonate $(\mathrm{NaCl}$, 119.39; KCl, 4.78; $\left.\mathrm{CaCl}_{2} .2 \mathrm{H}_{2} \mathrm{O}, 1 \cdot 71 ; \mathrm{KH}_{2} \mathrm{PO}_{4}, 1 \cdot 19 ; \mathrm{NaHCO}_{3}, 25.07 \mathrm{~mm}\right)$ described by Brinster (1965), supplemented with sodium pyruvate $(0.25 \mathrm{~mm})$ and crystalline bovine serum albumin $(1 \mathrm{mg} / \mathrm{ml})$. Potassium penicillin $\mathrm{G}$ $(50 \mathrm{U} / \mathrm{ml})$ and streptomycin sulphate $(50 \mu \mathrm{g} / \mathrm{ml})$ were added to safeguard sterility. When this culture system was incubated under $5 \% \mathrm{CO}_{2}$ in an air atmosphere, the oocytes formed polar bodies but with significantly lower efficiency than in drops under oil. Since the oil layer might provide a lower oxygen concentration by restricting gaseous exchange between atmosphere and medium, the effect of varying the oxygen concentration of the atmosphere on the proportion of oocytes that developed first polar bodies was studied.

Microtest Plate cultures were placed in small desiccators, which were evacuated to $60 \mathrm{~mm} \mathrm{Hg}$ and refilled five times with atmospheres containing the appropriate partial pressure of oxygen. The balance of the atmosphere was nitrogen, except for $\mathrm{CO}_{2}$ which was kept constant at $5 \%$. After incubation for 18 to $20 \mathrm{hr}$ at $37^{\circ} \mathrm{C}$, the proportion of oocytes which had formed polar bodies was recorded. Text-figure 1 shows that when no oxygen was added to the atmosphere, relatively few oocytes produced polar bodies. Maximum maturation, not significantly different from that observed under oil, with minimum variation occurred with 5 to $10 \%$ oxygen. Above this concentration, maturation 


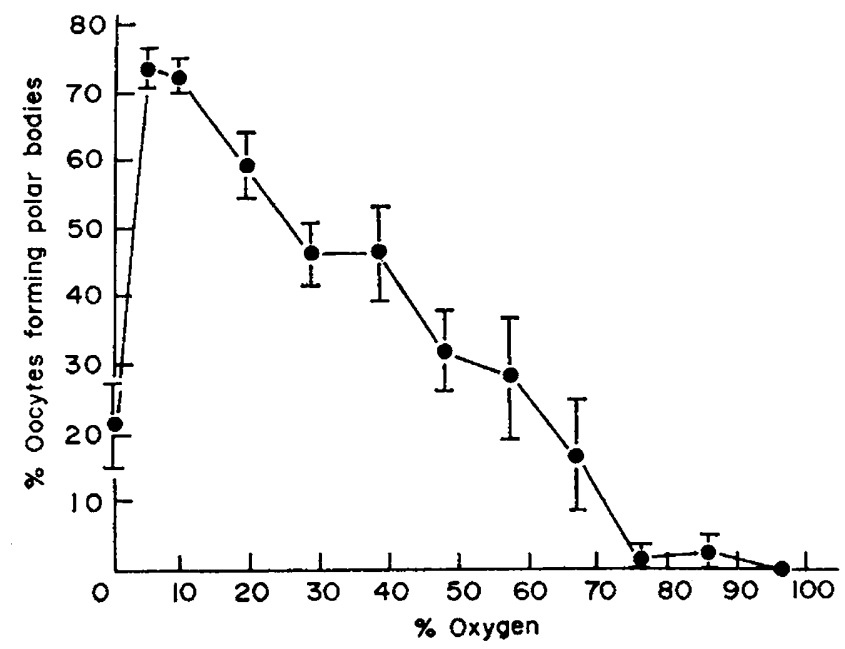

Text-Fig. 1. Effect of oxygen content of the gas phase on oocyte maturation. Each value is the average maturation of sixty oocytes, with S.E.M.

was reduced until at about $75 \%$ oxygen, hardly any of the oocytes formed polar bodies.

Having established that mouse oocytes would form polar bodies satisfactorily without an oil overlayer, provided the partial pressure of oxygen was kept at 5 to $10 \%$, the effect of eliminating the protein component from the medium was examined. Text-figure 2 shows that oocytes formed polar bodies without protein, but that the proportion of oocytes capable of doing so was reduced significantly. We also observed that, in the absence of protein, the oocytes were difficult to manipulate since they tended to float and to adhere to the

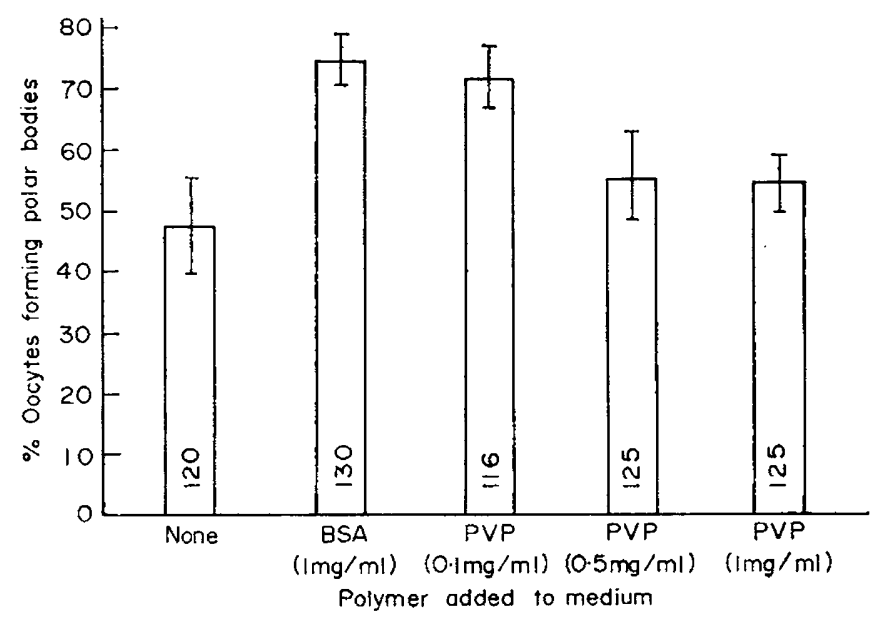

TexT-FIG. 2. Effect of omitting bovine serum albumin (BSA) from the medium, and of replacing this protein with polyvinylpyrrolidone (PVP), on the maturation of mouse oocytes. Number of oocytes tested and S.E.M. response are shown on each histogram figure. 
micropipette. Several years ago, Whitten (1957) reported a similar problem with cleavage stages of the mouse embryo. We found that PVP (Calbiochem Co., ave. mol. wt 40,000 ) at $0.1 \mathrm{mg} / \mathrm{ml}$ could substitute completely for bovine serum albumin with respect to the proportion of oocytes which formed polar bodies, but did not overcome the problems of manipulation. To do so, the concentration of PVP had to be raised to $0.5 \mathrm{mg} / \mathrm{ml}$. However, this concentration of polymer was somewhat inhibitory (see Text-fig. 2). The cause of this inhibition was not established, but apparently it is not the result of heavy metal contamination since EDTA $\left(10^{-7}\right.$ to $\left.10^{-3} \mathrm{M}\right)$ did not increase the proportion of oocytes forming polar bodies in the presence of $0.5 \mathrm{mg} \mathrm{PVP} / \mathrm{ml}$.

Oocytes which had formed polar bodies were stained with aceto-orcein by the procedure described by Donahue (1968). When PVP $(0 \cdot 1 \mathrm{mg} / \mathrm{ml})$ was substituted for protein in the medium, nineteen out of twenty-eight $(68 \%)$ of the oocytes with polar bodies displayed second metaphases which were normal in appearance compared with an only slightly greater proportion, seventeen out of twenty-three $(74 \%)$, when the medium contained $1 \mathrm{mg}$ bovine serum albumin/ml. Hence, even when deprived of a source of fixed nitrogen, a majority of oocytes was capable of reaching the metaphase of the second meiotic division, i.e. complete maturation occurs.

These experiments have provided a system by which mouse oocytes may be cultured without the need for an oil-cover, or for protein in the medium. They have also shown that the sensitivity of mouse cleavage embryos to $20 \%$ oxygen (Whitten, 1969) and their ability to develop into blastocysts without a fixednitrogen source (Cholewa \& Whitten, 1970) are already properties of the oocyte before ovulation.

\section{REFERENCES}

Biggers, J. D., Whittingham, D. G. \& Donahue, R. P. (1967) The pattern of energy metabolism in the mouse oocyte and zygote. Proc. natn. Acad. Sci. U.S.A. 58, 560.

BRINSTER, R. L. (1965) Studies on the development of mouse embryos in vitro. II. The effect of energy source. F. exp. Zool. 158, 59.

Gholewa, J. A. \& Whitten, W. K. (1970) Development of two-cell mouse embryos in the absence of a fixed-nitrogen source. 7. Reprod. Fert. 22, 553.

Donakue, R. P. (1968) Maturation of the mouse oocyte in vitro. I. Sequence and timing of nuclear progression. 7. exp. Zool. 169, 237.

Kennedy, J. R. \& Donakue, R. P. (1969) Human oocytes: maturation in chemically defined media. Science, N.Y. 164, 1292.

Whrtren, W. K. (1957) Culture of tubal ova. Nature, Lond. 179, 1081.

Whitren, W. K. (1969) The effect of oxygen on cleavage of mouse eggs. In: Abstracts of 2nd Ann. Meeting, Soc. for Study of Reprod., Davis, California, 1969, p. 29. 